\title{
Associativismo e Percepção do Mercado de Trabalho: uma amostra desta relação entre fisioterapeutas
}

\section{Associativism and Perception of the Job Market: a sample of this relation among physiotherapist}

Artigo

Original

Original

Paper

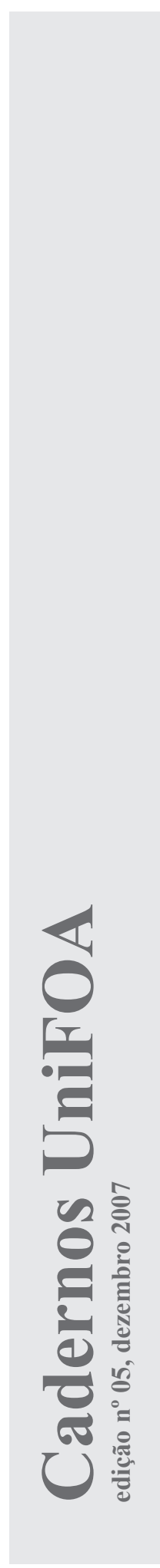

\author{
Maria Cristina de Carvalho Tommaso ${ }^{1}$ \\ Elidiane Aparecida da Silva ${ }^{2}$ \\ Gildelice Stival Poloniato ${ }^{2}$
}

Resumo

\section{Palavras-chaves: \\ Associativismo \\ Profissionalismo \\ Mercado de \\ Trabalho}

Este artigo pretende identificar o grau de associativismo entre fisioterapeutas e a percepção do mercado de trabalho na região sulfluminense para estes profissionais. Para FREIDSON (1994) o grau de associativismo reflete uma categoria organizada, que controla seu trabalho e quem a ele pode se credenciar. Este estudo mostra como fisioterapeutas percebem que o aumento do número de profissionais repercute-se no mercado de trabalho, o médio grau de associativismo entre os entrevistados, o grau de satisfação com os órgãos que os representam e suas expectativas para mercado de trabalho na região em que estão. A pesquisa aponta ainda, que as profissões mais antigas são modelo de profissionalismo. Enquanto isso, estudos de orientação de escolha profissional revelam a importância do comportamento dos profissionais na formação da identidade profissional. Portanto, de que forma estes sentimentos norteiam comportamentos e podem influenciar jovens que pretendem ingressar ou ingressaram recentemente na profissão?

\begin{abstract}
This article intends to identify the level of associativism among physiotherapists and the perception of the job market in the south area of Rio de Janeiro for those professionals. For FREIDSON (1994) the level of associativism reflects an organized category, which controls his work and to which he can accredit himself. This study shows how physiotherapists notice that the increase in the number of professionals impacts the job market, the medium level of associativism among the interviewees, the level of satisfaction with the parts that represent them and their expectations for the job market in the region where they are. The survey still shows that older professions are models of professionalism. In the meantime, career orientation studies present the importance of professionals' behavior in the formation of professional identity. Therefore, how do such feelings guide behaviors and may influence young people who intend to start or have already started in the profession?
\end{abstract}

\section{Introdução}

Este artigo pretende identificar uma possível relação entre o grau de associativismo entre fisioterapeutas e suas expectativas para o mercado de trabalho para a profissão.

Observa-se que a percepção de mercado de trabalho para fisioterapeutas no
Key words:

Associativism

Professionalism

Job Market

${ }^{1}$ Mestre - Fisioterapia - UniFOA

${ }^{2}$ Fisioterapeutas

Brasil, e neste caso na região sul fluminense, tem se modificado nos últimos anos. Há um discurso generalizado de que o mercado de trabalho para estes profissionais está saturado e a procura por esta formação profissional está decrescendo após e em decorrência 
do significativo crescimento da oferta de vagas nos últimos dez anos. Além disso é possível perceber também que apesar do aumento do número de profissionais, o grau de associativismo entre fisioterapeutas não esteja aumentando ou contribuindo para o fortalecimento da categoria profissional.

Entende-se por associativismo o grau de atração entre indivíduos com tendência de agregarem-se para assegurar uma condição favorável diante de ameaças do ambiente externo. [1].

A expressão associativismo designa por um lado a prática social da criação e gestão das associações - organizações providas de autonomia e de órgãos de gestão democrática dessa prática como assembléia geral, direção, conselho fiscal - e, por outro lado, a apologia ou defesa de associação, enquanto processo não lucrativo de livre organização de pessoas - os sócios, para a obtenção de finalidades comuns.

Quanto ao mercado de trabalho, a expansão do ensino universitário no Brasil após 1997 com a criação dos centros universitários gerou aumento significativo de oferta de vagas para a maioria dos cursos de graduação e conseqüentemente de alunos egressos, inclusive e principalmente para a fisioterapia. Talvez isto possa explicar a percepção generalizada de que o mercado de trabalho para a fisioterapia esteja saturado.

Para FREIDSON (1994) [2] , uma profissão estará mais segura quando detiver o controle sobre a determinação do número e das características daqueles que podem executar o trabalho.

Para LARSON (1977) [3], uma profissão que se auto-regula detém o controle sobre a produção de profissionais e sobre $\mathrm{o}$ mercado de trabalho. A autora considera que a gênese de um monopólio em um mercado de serviços está no controle instituído no ponto da produção de profissionais.

Assim sendo este estudo pretende identificar o grau de atração entre os profissionais através da análise de sua associação a grupos de interesse, sua satisfação com órgãos representativos e a percepção do mercado de trabalho através de pesquisa entre docentes, com experiência profissional e acdêmica acima de 10 anos, de uma IES privada do sul fluminense realizada no período entre 7 e 11 de maio de 2007.

\section{Considerações Teóricas eSuas Correlações com a Fisioterapia}

A partir de 1997, o Decreto Lei N.2.036 de 19 de Agosto de 1997, regulamenta a organização acadêmica e cria os centros universitários que dispõem de autonomia para criar, organizar e extinguir cursos e programas de educação superior, assim como remanejar e ampliar vagas nos cursos existentes. Anteriormente esta condição esteve relacionada exclusivamente às universidades. Mediante tal alteração, Instituições de Ensino Superior - IES privadas puderam oferecer livremente os cursos que entendiam ser de maior interesse seguindo a uma lógica mercadológica de oferta e demanda.

O censo de educação superior 2003 do Ministério da Educação apresenta um resumo do sistema de educação superior no qual percebe-se que o Brasil está entre os mais privatizados do mundo, isto é, $88,9 \%$ das 1.859 instituições de ensino superior no Brasil são particulares. Os dados do censo 2003 mostram que os cursos de graduação presenciais continuam em expansão, com acréscimo de 2.054 novos cursos em relação ao ano anterior.

É possível que, por esta razão, tenha havido um aumento significativo na oferta de cursos e número de vagas para muitas profissões, dentre elas a fisioterapia. Esta, muito provavelmente, e conforme aponta pesquisa realizada com alunos ingressos em curso de fisioterapia de IES privada, ocorreu em virtude de ser uma profissão com características muito próximas de outra mais antiga e que detém forte status na área da saúde como a medicina. Isto é, características como a autonomia obtida através de um corpo de conhecimento que a distingue e o reconhecimento pelo público em geral e a diversidade de áreas de atuação. [4]

Entretanto, a restrição de acesso ao mercado de trabalho, isto é, o excesso de oferta de profissionais em relação ao número de vagas no mercado de trabalho, passou a comprometer a atuação profissional. Ao contrário da medicina, a fisioterapia não detém a vantagem da clientela ilimitada e não encontra nas políticas públicas de saúde o mesmo respaldo de atuação. Não há ofertas de empregos públicos para a fisioterapia como há para médicos e enfermeiros. Estes também sofreram aumento significativo no 
número de profissionais, porém a oferta de emprego vem atendendo razoavelmente à demanda de profissionais. Importante ressaltar que de acordo com a Art. 16 do Decreto N. 2.036 de 19 de agosto de 1997, os cursos de medicina, odontologia e psicologia devem ser previamente recomendados pelo Conselho Nacional de Saúde, assim como cursos jurídicos, conforme Art 17 do mesmo decreto, devem ser recomendados pelo Conselho Federal da Ordem dos Advogados do Brasil para que o Ministério de Educação e do Desporto autorize sua abertura. Percebe-se que há um tratamento diferenciado para estas profissões que sugerem uma força política destas categorias com o objetivo de controlar a produção de profissionais.

Reconhecida como profissão em 1969 no Brasil, a fisioterapia apresenta um projeto de profissionalização semelhante ao de profissões mais antigas, porém parece não ser capaz de deter o mesmo nível de controle na produção de profissionais. De acordo com dados do Instituto Nacional de Estudos e Pesquisas Educacionais Anísio Teixeira - INEP a oferta de cursos de graduação em fisioterapia no Brasil passou de 212 em 1999 para 450 em 2006, sendo que 250 deles estão na região sudeste, 69 na região sul e 20 na região norte. Na região sudeste, dos 250 cursos oferecidos, 178 estão nos estados de São Paulo e Rio de Janeiro. (ANEXO A).

De acordo com dados do INEP observa-se aumento na oferta de vagas de 25.000 em 2000 para 57.133 em 2004, sendo que foram ocupadas em média 25.000 vagas numa tendência constante. $\mathrm{Na}$ região sul fluminense 1010 vagas foram ofertadas em 2001 para 823 ingressos e 820 vagas em 2003 para 533 ingressos.

Considerando que não houve oferta de empregos para fisioterapeutas, em instituições de saúde públicas e privadas, em consonância com número de profissionais graduados conforme dados do Ministério do Trabalho e do Emprego- MTE, é possível que haja superoferta de profissionais com conseqüências para a profissão como o desemprego, o subemprego ou o aumento de profissionais autônomos, além da insatisfação pessoal que poderá comprometer a identidade profissional.

Importante observar como se dá o controle de criação de novos cursos e como a profissão, através de seus órgãos representativos como conselhos, associações, sindicatos, reage a elas, assim como observar o grau de autonomia profissional, uma vez que é a auto-regulação, isto é, o controle sobre a produção de novos profissionais e sobre o modo como vão atuar, que pode aferi-la.

$\mathrm{Na}$ fisioterapia, assim como em quase todas as profissões e não menos nas da área da saúde, a criação de novos cursos e a determinação do número de vagas ofertadas são decididas dentro das instituições de ensino.

\section{A Auto-Regulação}

\subsection{O controle profissional sobre o número de profissionais}

"Uma profissão estará mais segura quando
detiver o controle sobre a determinação do
número e das características daqueles que
podem executar o trabalho."

(FREIDSON, 1994)

Para FREIDSON (1994): “não podem restar dúvidas de que a recente análise brilhante de Abbott (1988) do papel das reivindicações e disputas jurisdicionais na mudança dos destinos das profissões nos forçará a prestar mais atenção à interação entre ocupações contíguas (...) e o papel do Estado quase certamente será investigado de maneira mais completa do que no passado".

O reconhecimento dos cursos de graduação no Brasil é função do Ministério da Educação e do Desporto e, em alguns casos, esta função está associada à recomendação de instituições como conselhos representativos de categorias profissionais. Desta forma, pode-se inferir que a criação de novos cursos é objeto de apreciação do Estado e das disputas e pressões dentro e fora dele. Entretanto, embora todos os cursos de graduação passem pelo crivo da avaliação das condições de ensino, nenhum jamais foi impedido de funcionar mesmo com o aumento significativo do número de novos cursos a partir de 2003 conforme citado anteriormente. Este aumento de oferta de cursos e vagas gerou um atraso na visita dos avaliadores tendo sido, em alguns casos, posterior à colação de grau das primeiras turmas. Neste caso, os conselhos profissionais 
foram obrigados a aceitar a inscrição e efetuar registro de egressos de cursos ainda não reconhecidos pelo MEC. Este foi o caso de dezenas de cursos de fisioterapia em todo o Brasil, assim como de diversas outras categorias profissionais.

\subsection{O controle profissional sobre o exercício profissional}

O profissionalismo, (...), representa um método de organização do desempenho no trabalho. Ele difere do mercado livre e da burocracia porque gira em torno do princípio central de que os membros de uma ocupação especializada controlam seu próprio trabalho.

( FREIDSON, 1994)

FRIEDSON (1994) acredita que a questão central do poder profissional resida no controle do trabalho pelos próprios trabalhadores profissionais. Este controle é denominado autonomia profissional, um tipoideal de autonomia forte sustentada por um monopólio ocupacional que compreende diversas dimensões, mas que antes de tudo trata-se de um monopólio econômico no qual a profissão controla o recrutamento, o treinamento e credenciamento para poder regular diretamente o número de praticantes disponível para satisfazer a demanda.

Para FREIDSON (1994), a profissão pode ter um monopólio administrativo ou de supervisão sobre os assuntos da vida prática associados ao trabalho quando seus membros ocupam as classes organizacionais relacionadas com o estabelecimento de padrões de trabalho, assim como o direcionamento e a avaliação do trabalho.

O modelo profissional, segundo FREIDSON (1994), baseia-se na noção democrática de que as pessoas são capazes de controlar-se a si próprias por meios coletivos, cooperativos, e de que, no caso de um trabalho complexo, aqueles que o realizam estão em melhor condição quando podem controla-lo. $\mathrm{Na}$ medida em que o trabalho é especializado, complexo e desafiador, os profissionais têm maior probabilidade de comprometer-se com ele do que de alienar-se dele. Naquele caso, as pessoas encontram valor e interesse intrínsecos no trabalho em si, o que as leva a querer fazê-lo bem.
No caso da fisioterapia e da maioria das profissões da área da saúde, e diferentemente da medicina, cuja auto-regulação é feita por seus pares, o exercício profissional e sua autonomia dependem quase sempre da boa vontade dos empregadores. A flexibilidade e a liberdade que podem ter em seus empregos são função mais de políticas de pessoal do que da autonomia garantida por uma regulamentação fortemente implantada e aceita. Para LARSON (1977) as burocracias podem ser aliadas de uma ou mais profissões numa empresa, quando definem e legitimam os papéis a serem desempenhados através de uma hierarquia burocrática.

De que forma os órgãos representativos da categoria profissional vem se manifestando e reagindo ao crescente número de profissionais lançados no mercado semestralmente? O grupo profissional de fisioterapeutas participa da criação e do formato dos cursos de graduação?

LARSON (1977) diz ainda que a estrutura da profissionalização está dividida em dois processos: a padronização do conhecimento, no qual um corpo de conhecimento abstrato garantido através da formalização da linguagem cuja legitimidade cognitiva garante homogeneidade e uniformidade para a objetivação da profissão; e o controle de mercado que estará sujeito às mudanças econômicas e sociais contingentes.

\subsection{O controle profissional sobre o conhecimento profissional}

"A conexão com a racionalidade cognitiva
superior parece estabelecer a superioridade de
um gênero profissional(...)."

(LARSON, 1977)

Magali Larson considera que o centro do projeto de profissionalização é a produção de profissionais e este processo tende a ser centralizado e aliado à moderna universidade que tende a tornar-se o principal centro de produção do conhecimento profissional.

A codificação do conhecimento é importante pois despersonaliza e, portanto torna objetiva a idéia que envolve a prática profissional, segundo Larson, e tem poderoso efeito na unificação profissional porque permite uma padronização mais meticulosa da produção dos profissionais.

O controle e a monopolização 
da educação profissional relativamente padronizada é a forma de controle e monopolização das oportunidades em um mercado de serviços ou trabalho assim como de status e trabalho numa hierarquia ocupacional.

Apesar da padronização do conhecimento profissional na fisioterapia e da exclusividade do exercício de algumas tarefas conforme previsto em decretolei de regulamentação, o controle sobre o credenciamento destes profissionais parece comprometer esta função a ponto de não ser garantida na realidade. Se não há controle sobre a produção de profissionais, e como há diferentes graus de qualificação obtidos em diferentes instituições formadoras, é possível que esta padronização do conhecimento esteja se perdendo e não alcance os objetivos que a gerou.

\section{$3.4 \mathrm{O}$ controle sobre o mercado de trabalho}

\begin{abstract}
"A superprodução de profissionais pode causar a queda do preço dos serviços e do trabalho, e resulta em desemprego ou subemprego de especialistas e de trabalhos altamente treinados."
\end{abstract}

(LARSON, 1977)

O problema do aumento do número de praticantes de uma profissão é citado por Friedson (1994) como um sinal das transformações pelas quais as profissões estão passando. Além disso, o autor diz que o estado da economia, que está fora do controle das profissões, pode afetar seriamente a posição de seus membros no mercado.

Larson afirma que a estrutura de um mercado profissional está determinada pela estrutura social maior na qual está situada, ou seja, o estágio de desenvolvimento econômico, o volume e distribuição da renda nacional, a estrutura de classe e a composição étnica, a média de padrão de vida, a natureza do estado e suas políticas e a ideologia incluindo uma variedade de tradições culturais que definem o potencial e a dinâmica do mercado de uma profissão.

A institucionalização da produção de profissionais e sua padronização podem favorecer o controle sobre o mercado de trabalho, porém se apesar da demanda ser grande e estável, a profissão não consegue regular o suprimento de profissionais através do controle de sua admissão e credenciamento, sua posição no mercado pode ser minimizada e enfraquecida

Para FREIDSON (1994) o trabalho autônomo, ao qual muitos fisioterapeutas recorrem como alternativa em um mercado de trabalho restrito, quando em um mercado de trabalho saturado, permite pouca autodeterminação de tarefas, ao passo que um mercado de trabalho rarefeito fortalece enormemente a posição do empregado. Para ele, a legislação é o método mais eficaz de controlar as circunstâncias de trabalho do trabalhador autônomo do que a negociação coletiva.

Para Larson, neste tipo de mercado como o de profissionais, a gênese está no controle primeiramente instituído no ponto da produção de profissionais. A superprodução de profissionais pode causar a queda do preço dos serviços e do trabalho, e resulta em desemprego ou subemprego de especialistas e altamente treinados para o trabalho. Como se comporta o mercado de trabalho para fisioterapeutas nos últimos anos? Qual o grau de desemprego e subemprego para a fisioterapia?

Para Friedson, a nova sociedade, emergente, está baseada no conhecimento sendo que autoridade da expertise institucionalizada estará presente na idéia de profissionalização, forma pela qual se organiza a posição dos profissionais no mercado de trabalho. Identificar as forças profissionais e formas de sua manutenção poderá ser uma estratégia de adaptação e sobrevivência às atuais mudanças no mercado de trabalho.

Para ABBOTT (1989)[5] a vida profissional está caracterizada por dois processos: a competição jurisdicional entre as profissões e as relações interprofissionais, sendo o poder dos sistemas de conhecimento das profissões sua habilidade de abstração em definir velhos problemas de uma nova maneira, o que possibilita a sobrevivência de uma profissão.

\footnotetext{
“A gênese natural de um monopólio em um mercado de serviços está no controle instituído no ponto da produção de profissionais."
}

(LARSON,1977) 
Para FRIEDSON (1994), dentre as diversas noções de profissão, a expertise, o credencialismo e a autonomia são dimensões, que em maior ou menor grau, estão relacionadas com todas elas. Estas dimensões estão, por sua vez, relacionadas ao controle sobre a alocação de tarefas, isto é, o poder de planejar, alocar e coordenar as tarefas em torno dos serviços profissionais e sobre a determinação de quem pode realizá-las conforme suas próprias metas políticas e de suas necessidades administrativas.

O aumento do número de profissionais pode comprometer o exercício profissional na medida em que estes não encontram proporcionalmente as oportunidades no mercado de trabalho. Por esta razão, problemas como o desemprego e o subemprego podem ser gerados e ocasionar mudanças na percepção de valor da profissão pelos usuários e pelos próprios profissionais, causando mudanças na identidade profissional. Este parece ser o caso da fisioterapia, o aumento de oferta de vagas no ensino de graduação gerou um aumento no número de profissionais que não encontraram no mercado de trabalho alocação suficiente.

Para FREIDSON (1994), quando os membros das profissões têm seus interesses materiais garantidos por seu controle sobre o trabalho e por sua posição protegida no mercado, estes membros conseguem desenvolver um profundo compromisso vitalício e uma identidade com seu trabalho que se transforma num interesse central de vida.

"As ocupações são consideradas sempre em relação às pessoas que as exercem.“

(BOHOSLAVSKY, 1980)

As identificações com profissionais, segundo BOHOSLAVSKY (1980)[6], veiculam não somente uma tonalidade afetiva mas também os atributos sociais que estes profissionais detêm. Para ele, as relações, gratificantes ou frustradoras, com pessoas que desempenham papéis sociais com as quais a criança se identifica, consciente ou inconscientemente, tendem a pautar o tipo de relação com o mundo adulto em termos de ocupações. Portanto, as ocupações que fazem parte do espaço psicológico das pessoas jamais gozam de neutralidade afetiva.

\section{O Associativismo}

O associativismo seria fundamental para a existência e manutenção de um regime democrático:

Nos países democráticos a ciência do associativismo é a ciência -mãe ; o progresso de todas as outras depende do progresso daquela. Entre as leis que regem as sociedades humanas, existe uma que parece mais precisa e clara que todas as outras. Para que os homens permaneçam civilizados ou assim se tornem, é preciso que entre eles a arte de se associar se desenvolva e aperfeiçoe na medida em que cresce a igualdade de condições.

(TOCQUEVILLE ,1987) [7]

O momento histórico hoje vivido exige uma mudança de comportamento do ser humano, estimulando-o ao exercício de habilidades para enfrentar os novos e grandes desafios pessoais e empresariais. Presenciamos pessoas físicas e jurídicas que buscam, nas ações coletivas, respostas aos seus problemas, interesses, objetivos e necessidades comuns, unindo-se em cooperativas, associações e outras formas afins.

(SETEC, 2007) [8]

Observa-se que a constituição de uma associação ou cooperativa é desprovida de qualquer complexidade, porém, são constantes os fracassos e os desvios dos objetivos que as originaram. O que se observa é que não basta simplesmente a manifestação superficial. É indispensável, para o bom desempenho de qualquer empreendimento, aperfeiçoar a consciência de cooperação e a qualificação profissional dos associados, dirigentes, conselheiros e colaboradores, demonstrandolhes, com linguagem adequada e alicerçada em fatos de sua vivência, que a sua entidade associativa é uma obra comum, onde a ação e a participação são conjugadas para o bem coletivo.

Para KERSTENETZKY (2007)[10] a participação política é tributária do ativismo associativo. Em momento de grande entusiasmo pela experiência norte-americana, Tocqueville proclamara, em Democracy in America, o sucesso da democracia norteamericana o melhor fruto de sua exuberante vida associativa, responsável quer pelo cimento social quer pela prática de uma 
peculiar concepção de autogoverno.

No Brasil, a cultura de descrença na força mobilizadora das massas torna grupos mais enfraquecidos pela desagregação e à mercê de outros, mais organizados que conquistam, por esta razão, o poder decisório.

No caso da fisioterapia não é diferente, percebe-se, assim como em outras profissões, que o sentimento de desagregação é significativo e o aumento do número de profissionais nos últimos anos pode ter potencializado este sentimento. Observa-se nos discursos acadêmicos uma percepção de que os profissionais não se associam tanto o quanto poderiam, para garantir a segurança do exercício profissional. Ao mesmo tempo, e paradoxalmente, estes mesmos profissionais parecem não se interessar por ações associativas ou movimentos de solidariedade profissional.

\section{Materiais E Métodos}

O Banco Mundial (2000) [10] criou um survey sobre capital social - entidade de natureza multi-dimensional definido em termos dos grupos, redes, normas e confiança de que as pessoas dispõem para fins produtivos. Isto é, a forma como se associam a fim de alcançarem objetivos comuns e que podem ser pessoais. Neste instrumento de medição do capital social associativismos organizaramse seis dimensões que determinariam o grau de associativismo entre grupos ou pessoas de uma mesma comunidade: grupos e redes; confiança e solidariedade; ação coletiva e cooperação; informação e comunicação; coesão e inclusão social e autoridade e ação política. Estas dimensões apontam para a importância das redes formadas pelas pessoas como associações e sindicatos, a relação de confiança entre membros de um grupo e o grau de solidariedade entre eles expressos também pela quantidade de ações coletivas e de cooperação. Além disso, a comunicação entre os membros estará mais facilitada se houver meios específicos através de relações mais estreitas proporcionadas por instrumentos gerados nas associações. A dimensão de coesão e inclusão social aponta as formas de divisão e diferenças que podem levar ao conflito. Quanto à autoridade e ação política este questionário mostra a importância de se deter certo controle sobre instituições e processos que afetam diretamente o bem-estar do grupo verificando o sentimento de satisfação e eficácia pessoal além da capacidade de influenciar tantos eventos internos ao grupo como respostas políticas mais amplas.

Baseados nos princípios e dimensões deste questionário, desenvolvemos um outro mais simplificado que pretendeu identificar o grau de envolvimento e satisfação com os órgãos representativos da categoria profissional e as perspectivas para o mercado de trabalho futuro. Isto é, a pesquisa pretendeu identificar a percepção do mercado de trabalho para a fisioterapia e o grau de associativismo destes profissionais. (ANEXO B)

Foi realizada pesquisa descritiva com perguntas fechadas e abertas com 12 profissionais de fisioterapia que exercem função docente de supervisão de estágio em IES privada em uma cidade do sul fluminense. Todos têm experiência profissional e docente de período acima de 10 anos, o que sugere um relativo grau de discernimento em virtude da experiência acadêmica e profissional anterior ao período de expansão universitária.

\subsection{Discussão de Resultados}

Dos 12 fisioterapeutas entrevistados, a faixa etária está entre 29 e 48 anos e 83,3\% (10) são do sexo feminino. Esta parece ser uma tendência nacional de "feminilização" das profissões antigamente chamadas de "paramédicas".

Todos são oriundos de curso de graduação de IES privada, considerando que são graduados com mais de 10 anos de experiência e na época não havia cursos oferecidos por universidades públicas. Dos entrevistados $16,6 \%$ (2) tem pós-graduação de nível stricto senso. Deve-se considerar que não há cursos de pós-graduação em nível de mestrado ou doutorado na região e o professor deve deslocar-se para grandes centros, como a cidade do Rio de Janeiro distante 100 km, a fim de aumentar seu grau de qualificação.

O tempo de experiência profissional varia entre 27 e 6 anos. Todos exercem docência em curso de graduação de fisioterapia, sendo que 41,5\% (5) têm vínculo empregatício com outra empresa, 58,1\% (7) são autônomos e $16,6 \%$ (2) prestam serviços. Neste caso 83,3\% (10) dos 12 entrevistados acumulam mais de 
uma função profissional. Todos, isto é, 100\% percebem mais de R\$ 2.000,00 mensais, ou seja, R\$ 24.000,00 anuais.

Quanto ao mercado de trabalho para a fisioterapia 49,8\% (6) consideram-no saturado, 33,2\% (4) consideram o mercado de trabalho promissor e 16,6\% (2) percebemno estável. Dos entrevistados, 16,6\% (2) acrescentaram palavras como "instável” e "em crise" para qualificar o mercado e 66,4\% (8) acrescentaram expressões quanto ao mercado de trabalho da seguinte forma:

Tabela 1

\begin{tabular}{|l|}
\hline - tende à estabilização \\
\hline - falta de oportunidade na região \\
\hline - momento de incerteza \\
\hline - derrotismo entre os alunos \\
\hline - subemprego \\
\hline - aumento da expectativa de vida \\
\hline - alunos carentes \\
\hline - excesso de cursos na região \\
\hline
\end{tabular}

Quanto à categoria profissional que serve como modelo de profissionalismo, dos 12 entrevistados 49,8\% (6) citam o direito, 33,2\% (4) dos entrevistados citam a medicina e $8,3 \%$ (1) cita a odontologia e um não opinou. Interessante observar que estas são as profissões que detêm o poder de recomendar ou não a abertura de novos cursos conforme citado anteriormente. Esta condição era desconhecida pelos entrevistados e foi observada após terem respondido ao questionário e terem sido perguntados sobre ela.

Dos 12 entrevistados, 16,6\% são associados da Associação Brasileira de Ensino em Fisioterapia - ABENFISIO, porém todos estão inscritos no Conselho Regional de Fisioterapia e Terapia Ocupacional CREFITO-II, órgão fiscalizador do exercício profissional da categoria e obrigatório para o exercício profissional. Dos 12 entrevistados, $66,4 \%$ (8) pertencem ou são associados a outro órgão de representação da classe profissional e $33,2 \%$ (4) não pertencem ou são associados a outros órgãos de representação da classe.

Após explicação sobre o que é associativismo, 74,7\% (9) dos entrevistados consideram médio o grau de associativismo na profissão, 8,3\% (1) consideram alto e 16,6\% (2) consideram-no baixo.
Entretanto, 64\% sentem-se insatisfeitos com o órgão que os representa, $16 \%$ estão indiferentes a esta representação e $8 \%$ estão satisfeitos com ela.

\section{Conclusão E Sugestões}

A revisão literária aponta para importância do controle sobre as condições de trabalho de uma categoria assim como a importância do associativismo como forma de exercer esse controle. Entretanto, embora os resultados da pesquisa mostrem que há uma percepção de mercado de trabalho saturado entre os entrevistados, o grau de associativismo é baixo e em consonância com a insatisfação com os órgãos de classe que os representam. Os entrevistados não têm participação significativa na coletividade como, por exemplo, não pertencem à associação de ensino da categoria apesar de todos serem docentes há mais de 10 anos. Isto pode apontar para a ineficiência do grupo organizador da associação no sentido de agregar indivíduos para o interior do grupo ou ainda, pode apontar para o desinteresse dos fisioterapeutas em dela participar por diversas razões que caberiam ser pesquisadas.

Vale ressaltar também que a mesma pesquisa deve ser realizada com outros grupos profissionais. É provável que as condições levantadas na pesquisa não sejam exclusivas da categoria de fisioterapeutas. Pesquisas mostram que a categoria apontada pelos entrevistados como modelo de profissionalismo também está insatisfeita com o processo de desprofissionalização por ela percebida nos últimos anos. [11]

Através da revisão literária, que identifica forças que regulam o mercado de trabalho e a importância do associativismo para as profissões, os resultados da pesquisa apontam para a necessidade do incremento da discussão dentro do grupo profissional para o desenvolvimento de ações coletivas. Essas ações poderiam promover o fortalecimento do sentimento de pertencimento, fundamental para a coesão de indivíduos e para a promoção de ações de interesse comum.

Propomos, a partir da necessidade do desenvolvimento de novas alternativas para superação das crises dentro das profissões, que o associativismo seja um caminho para a abertura de novas oportunidades. Importante 
ressaltar que os docentes, reconhecidamente, são influentes na formação de novos profissionais. Não apenas por participarem diretamente da vida acadêmica, qualificando os futuros profissionais, replicando seus conhecimentos através das práticas disciplinares, mais que isso, por serem os profissionais que transmitirão crenças e valores que nortearão o comportamento futuro daqueles cuja formação lhes é são confiada.

\section{Considerações Finais}

A expansão do ensino superior é um fenômeno cíclico na história das sociedades industrializadas e em processo de industrialização, isto é, profissões se desenvolvem, crescem e são valorizadas em detrimento de outras na medida em que atendem à demanda do mercado que por sua vez está vinculado às estratégias políticas e econômicas contingentes. Dessa forma observa-se que profissões de todas as áreas sofrem influência destas demandas e são criadas, fortalecidas, reformuladas e mesmo extintas ao longo da história.

Com a fisioterapia não é diferente, reconhecida desde 1969, seu processo de profissionalização tem um desenho social muito próximo das teorias das profissões, e atualmente passa por um profundo processo de reformulação no qual a percepção de seu valor varia consideravelmente entre seus representantes, os demais profissionais da saúde e os indivíduos da coletividade.

Entretanto, numa observação mais apurada e em consonância com os acontecimentos dos últimos cinco anos, pode-se dizer que há uma significativa reação desta categoria mediante o aumento do número de seus profissionais. De acordo com dados órgão fiscalizador, o Conselho Federal de Fisioterapia e Terapia Ocupacional - COFFITO - há uma crescente procura e solicitação de abertura de associações, sindicatos e demais instituições representativas. Neste ano, pela primeira vez foi criada uma confederação das associações de classe, com a adesão de mais de 200 associações distribuídas pelo país. Além disso, projetos de lei tramitam no Senado Federal e nas Assembléias Legislativas e na Conferências Municipais de Saúde tratando de assuntos que atendem aos interesses da classe.

Assim sendo, e de acordo com a teoria do aumento da densidade demográfica como fator gerador de forças coercitivas, pode-se concluir que há fortes chances de haver um caráter positivo no aumento do número de profissionais para a categoria profissional, quando estes se associam.

\section{GRÁFICO 1}

Tempo de Experiência Profissional: Relação entre Ano de Graduação e Idade dos entrevistados

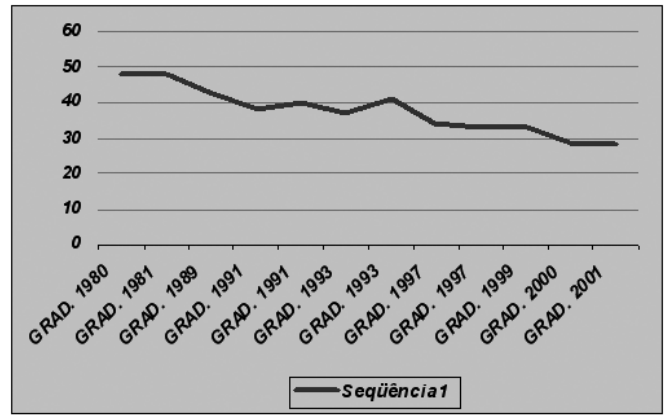

GRÁFICO 2

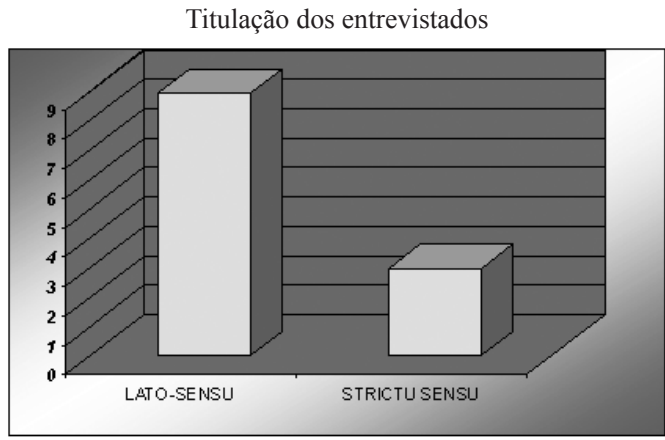

GRÁFICO 3

Como os entrevistados percebem o Mercado de Trabalho para a fisioterapeutas na região sulfluminense

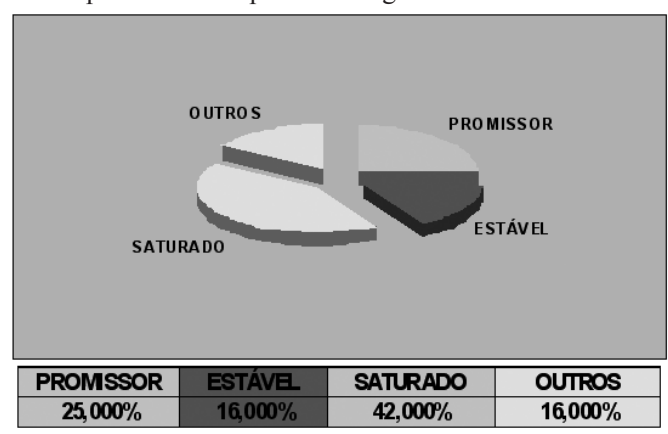

GRÁFICO 4

Como os entrevistados percebem o grau de coleguismo entre fisioterapeutas

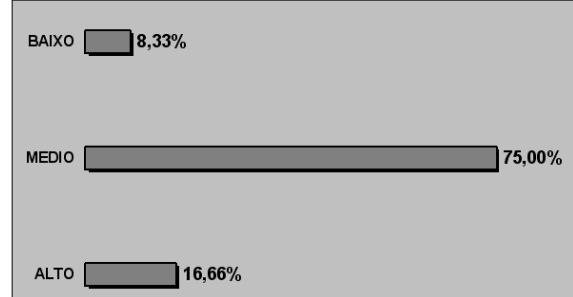




\section{Atividade Profissional dos entrevistados}

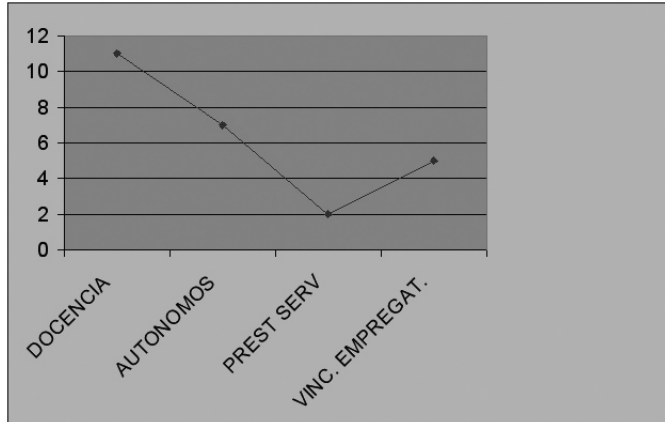

GRÁFICO 6

Entrevistados que pertencem a Órgãos de

Classe

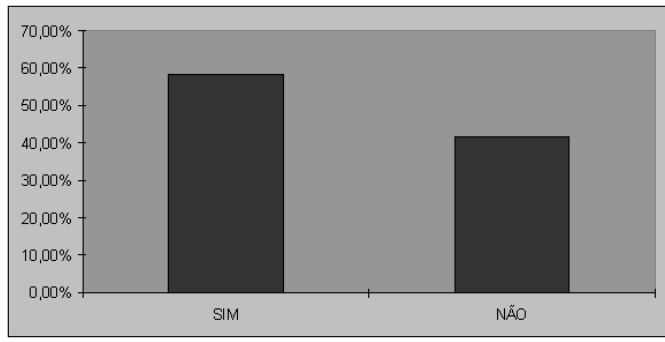

GRÁFICO 7

Categoria fortemente profissionalizada para os entrevistados

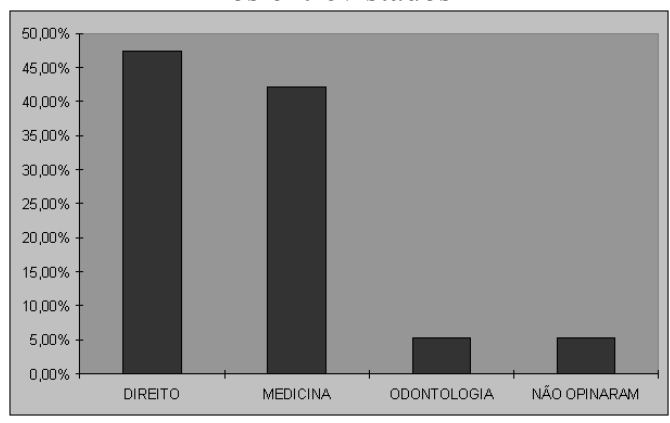

GRÁFICO 8

Satisfação dos entrevistados com o órgão de classe que os representa

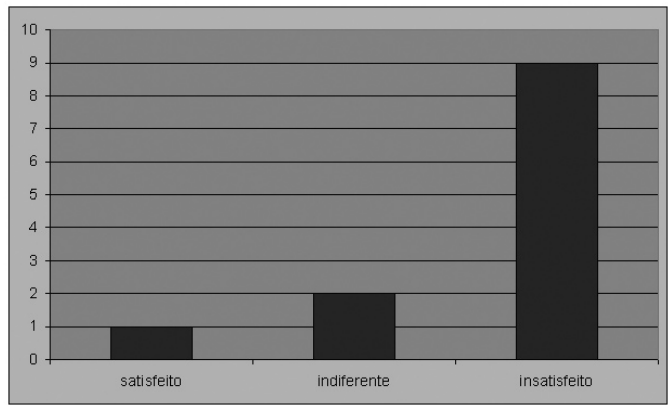

Entrevistados associados da ABENFISIO

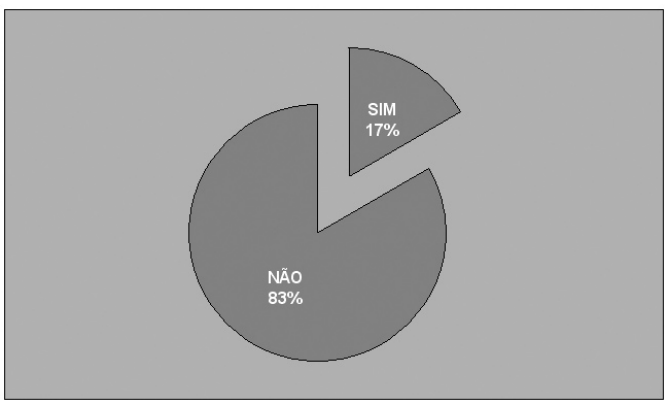

\section{Referências}

WOOLCOCK, MeNARAYAN, D. Capital social: implicaciones para la teoria, la investigación y las políticas sobre desarrollo. Washington, D.C : Banco Mundial, 2000.

FREIDSON, Eliott. Renascimento do Profissionalismo: teoria, profecia e política. São Paulo: EDUSP, 1994.

ProfessionalizationandtheOrganization of Middle-Class Labour in Postindustrial Society. In Paul Halmos (org.), Professionalization and Social Change. Staffordshire, The University of Keele, 1973.

La Profesion Médica. Un Estudio de Sociología del Conocimiento Aplicado. Tradução de Maria Isabel Hirsch. Barcelona, Ediciones Península, 1984.

LARSON, Magali Sarfatti. The Rise of Professionalism: a sociological analysis. Berkeley: University of California Press, 1977.

TOMMASO. M.C.C. A relação entre escolha e satisfação por uma profissão: o caso da fisioterapia. Anais do II Congresso Brasileiro de Coordenadores de Curso de Fisioterapia. ABENFISIO. Vitória, 2003.

ABBOTT, Andrew. The System of Professions: $\mathrm{Na}$ Essay on the Division of Expert Labor. Chicago: University of Chicago Press, 1989.

BOHOSLAVSKY, Rodolfo. Orientação Vocacional:A estratégia clínica. São Paulo: Martins Fontes, 1977.

TOCQUEVILLE, Alexis de. A Democracia na 
KERSTENETZKY, Celia Lessa. Sobre associativismo, desigualdades e democracia. Rev. Brasileira de Ciências. Sociais. v.18 n.53 São Paulo out. 2003

BANCO MUNDIAL. Questionário Integrado para Medir Capital Social (QI-MCS). Woolcock et alli. 2003.

MACHADO, M.H. Os médicos e sua prática profissional: as metamorfoses de uma profissão. Tese apresentada ao Instituto Universitário de Pesquisas do Rio de Janeiro - IUPERJ, 1996

\section{Referências Complementares}

BARBOSA, Maria Lígia de Oliveira. As Profissões no Brasil e sua Sociologia.

A Sociologia das Profissões: em torno da legitimidade de um objeto. BIB. N. 36, 20. semestre, 1993. p.3-30.

BOCK, Ana Mercês Bahia...(et al.). A Escolha Profissional em Questão. 2 ed. São Paulo: Casa do Psicólogo, 1995.

BURRAGE, Michael \& TORSTENDAHL, Rolf. Professions in Theory and History: rethinking the study of the professions.
COELHO, Edmundo Campos. As Profissões Imperiais no Brasil: Medicina, Engenharia e Advocacia no Rio de Janeiro. 1822-1930. Rio de Janeiro: Record, 1999.

CARNEIRO, João Marinônio Aveiro. Metodologia do Ensino Superior. Rio de Janeiro: Folha Carioca, 2000.

MARINHO, Marcelo Jacques M. da Cunha. Profissionalização e Credenciamento: a política das profissões. Rio de Janeiro: SENAI/DN/DPEA, 1986.

MACHADO, Maria Helena. Profissões de Saúde. Rio de Janeiro: FIOCRUZ, 1995.

RODRIGUES, Maria de Lurdes. Sociologia das Profissões. São Paulo: Celta, 2004.

SCHWARTZMAN, Simon. Os Desafios da Educação no Brasil. São Paulo: EDUSP, 1997.

STARR, Paul. La Transformación Social a la Medicina en los Estados Unidos de América.

SENETT, Richard. A Corrosão do Caráter. Rio de Janeiro: Record, 1999.

WILLIAM, Bridges. Um Mundo sem Empregos: os desafios da sociedade pós-industrial. São Paulo: Makron Books, 1995.

\section{ANEXO A}

Número de cursos de graduação em Fisioterapia por União Federativa e Capital comparados aos cursos de Administração e Medicina

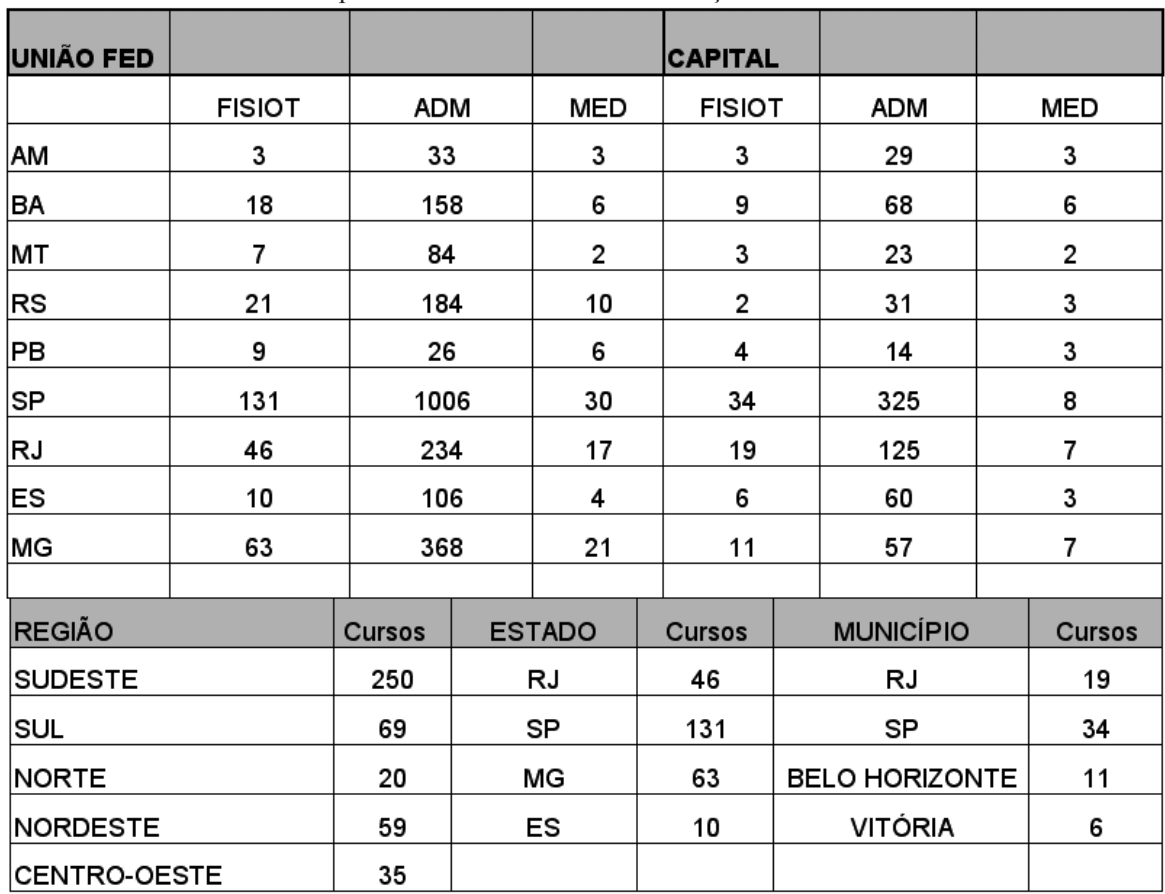


Associativismo e Percepção de Mercado de Trabalho: uma amostra desta relação entre fisioterapeutas.

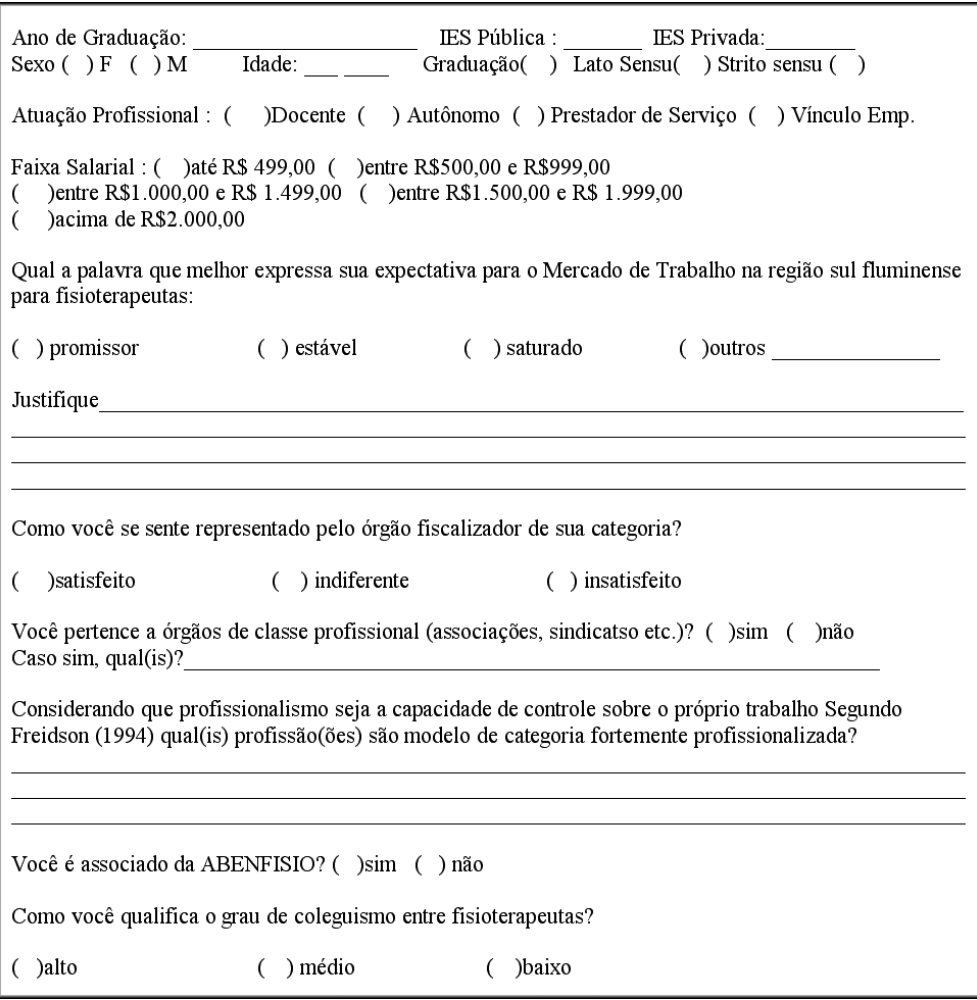

Informações bibliográficas:

Conforme a NBR 6023:2002 da Associação Brasileira de Normas Técnicas (ABNT), este texto científico publicado em periódico eletrônico deve ser citado da seguinte forma:

TOMMASO, M. C. C.; SILVA, E. A.; POLONIATO, G. S.. Associativismo e Percepção do Mercado de Trabalho: uma amostra desta relação entre fisioterapeutas. Cadernos UniFOA, Volta Redonda, ano 2, $\mathrm{n}^{\circ}$. 5, dez. 2007. Disponível em: <http://www.unifoa.edu.br/pesquisa/caderno/edicao/05/68.pdf> 